International Journal of Current Microbiology and Applied Sciences

ISSN: 2319-7706 Volume 8 Number 01 (2019)

Journal homepage: http://www.ijcmas.com

\title{
Population Dynamics and Management of Mango Fruit Fly Bactrocera dorsalis (Hendel) (Diptera: Tephritidae)
}

\author{
E. Sumathi ${ }^{1 *}$, R. Manimaran ${ }^{2}$, M. Nirmala Devi ${ }^{3}$, M. Ilamaran ${ }^{4}$ and R. Agila $^{5}$ \\ ${ }^{1}$ Department of Agricultural Entomology, Tamil Nadu Agricultural University, \\ Coimbatore, India \\ ${ }^{2}$ Department of Plant Breeding and Genetics, Tamil Nadu Rice Research Institute, \\ Aduthurai, India \\ ${ }^{3}$ Department of Agricultural Extension, Agricultural College and Research Institute, \\ Vazhavachanur, India \\ ${ }^{4}$ Department of Food Science and Nutrition, Home Science College and Research Institute, \\ Madurai, India \\ *Corresponding author
}

\section{A B S T R A C T}

\section{Keywords}

Bactrocera dorsalis, Population Dynamics, Fruit yield, Trap, BCR

Article Info

Accepted:

17 December 2018

Available Online:

10 January 2019
The mango fruit fly, Bactrocera dorsalis (Hendel) (Diptera: Tephritidae) is a destructive polyphagous pest, posing threat to mango growers in Papparampakkam village of Tiruvallur District in Tamil Nadu. Population dynamics of fruit fly and yield were recorded in Papparampakkam village of Tiruvallur district during 2014-15. The results showed that trap catches was high, 839.1 fruit flies per trap during July 2014, followed by August, 2014 (563.8 fruit flies /trap). The fruit fly population was low during January, 2015 to April, 2015. Mango fruit yield was found to be high $143 \mathrm{q} / \mathrm{ha}$ in IPM plot due to the adoption of IPM strategy viz., field sanitation, soil raking and installation of methyl euginol fruit fly traps @ 25 /ha and in Non IPM plot the fruit yield was observed to be 112 $\mathrm{q} /$ ha. Benefit cost ratio was also found to be high in IPM plot $(1: 11.5)$ when compared to Non IPM plot.

\section{Introduction}

The production of mango is limited by many insect pests which are responsible for the low yield and poor quality of fruits. In India, about 250 insects and mite pests have been reported in mango. Out of these, 30 pests are economically important, capable of causing considerable loss to crop growth and yield (Tandon and Verghese, 1985). Among these, the most destructive and devastating pest is the Oriental fruit fly, Bactrocera dorsalis (Hendel) (Diptera: Tephritidae). The female generally insert its eggs in the ripening fruit of the host plant, but also in the young fruit which have fallen post abscission. The larvae 
or maggots develop in the flesh of untreated fruit by digging tunnels which provide opportunities for secondary infections when the maggot emerges from the fruit. The growth of the maggot accelerates the maturation of the fruit, which detaches and falls to the ground. Pupation takes place in the top layer of the soil. Upon emergence, the adult soon starts looking for the nourishment it needs to reach sexual maturity, mate, and lay eggs. The lack of basic knowledge about the biology of fruit flies and safer management strategies among farmers is a major constraint to increase production (Sithanantham, 2004). Mango growers suffered heavy losses due to fruit fly infestation.

Extensive studies on the incidence and distribution of fruit flies throughout South Asia was done by Kapoor et al., (1976) and Agarwal and Kapoor (1985). It was first recorded in Taiwan in 1907 (Lee, 1988). Now, this species is distributed throughout the AsiaPacific Region (Clarke et al., 2005; Hsu, 1973; Ye, 2001).

Fruit flies are the most devastating insect pests having a foremost influence on global agricultural products, effecting yield losses and dropping the value and marketability of horticultural crops. The incidence of fruit fly, not only reduces the yield and quality but also cause considerable economic loss. Mumford (2001) and Mishra et al., (2012) reported a crop loss of upto Rs. 2945 crores per annum in mango, guava, sapota and citrus in India. The yield loss due to fruit flies varies between 30100 per cent depending on the fruit species and season (Dhillon et al., 2005). Economic significance of fruit flies in India was reported by Verghese et al., (2002), causing a yield loss of 2.5 to 59.0 per cent depending on the variety. They reported that the crop loss due to B. dorsalis varies with season and region. They observed higher percentage infestation on varieties Banganapalli and Totapuri with mean infestation of 46.0 and $59.0 \%$, respectively and least infestation on varieties Dushehari and Langra. The extent of damage may go upto 80 per cent when the pest incidence occurs in an epidemic form (Abdullah et al., 2002). It also caused an indirect loss by affecting the export market due to strict quarantine restrictions of importing nations (Serem, 2010). It affects both quantity and quality of mango fruits and can be considered as a major constraint to mango production. Pre and post harvest yield loss of 27 - 80 per cent was recorded in mango (Abdullah et al., 2002). In Tiruvallur district mango is cultivated in an area of 10,000 ha with the productivity of is low. Mango fruit fly is the major pest and its damage leads to 30 per cent yield loss. Mango growers rely only on insecticides for the management of fruit flies. Indiscriminate and injudicious use of pesticides creates environmental pollution and pesticide residue problems (Rahiman et al., 1986). In this connection present situation warrants an ecofriendly pest management strategy. Male annihilation technique (MAT) using methyl eugenol as an attractant is considered as an ecofriendly and safe management measures for fruit flies.

Studies on the population build up of the pests are essential for its successful management. Fruit abundance and availability were the main factors for population buildup of fruit flies (Vargas et al., 1983). A positive relationship between peak fruit fly population and time of ripening of fruit was observed in Taiwan (Chiu and Chu, 1986). Therefore, affordable and environment friendly IPM options should be adopted to tackle the problem. Verghese et al., (2004) warrants the need of integrated approach for fruit fly management involving IPM strategy including field sanitation, soil raking, bait traps and male annihilation traps. In this context, 10 front line demonstrations were made to 
disseminate the mango fruit fly trapping technology to the farmers of Tiruvallur district and population dynamics of fruit fly has been studied for its effective management.

\section{Materials and Methods}

A survey was made during 2014 in Papparampakkam village of Tiruvallur district, Tamil Nadu on the incidence of mango fruit fly and yield loss. Pest incidence was recorded by collecting ten fruit samples selected at random from each plant during the peak fruiting season and the percentage infestation was recorded.

Studies on population dynamics of mango fruit fly was conducted in ten mango orchards in Papparampakkam village during 2014-15 and the size of the orchard was 1 ac. Methyl eugenol traps were used for monitoring the pest population. In IPM field,traps were installed@25 / ha. and kept in 10 mango orchards during July, 2014 and lures were replaced each month.

Other IPM strategies viz., field sanitation and soil raking also done. By adopting paired plot technique the trial was laid out. Adjacent to IPM plot, a Non IPM plot was maintained in which farmers spray insecticides viz., Imidaclorid, chlorpyriphos, lambda cyhalothrin etc. Trap catches were taken at weekly intervals to study the population dynamics of the pest. Pest incidence was recorded by collecting 100 fruit samples selected at random from each orchard during the peak fruiting season and the per cent infestation was recorded. Fruit yield at each picking was recorded and $\mathrm{B}: \mathrm{C}$ ratio was worked out.

\section{Data analysis}

The experimental results were subjected to statistical analysis adopting Fisher's method of analysis of variance as outlined. Testing of significance was done and values are given at 5 per cent level of significance.

The yield differences between IPM and Non IPM plots were calculated and data were subjected to appropriate statistical analysis (' $t$ ' test)

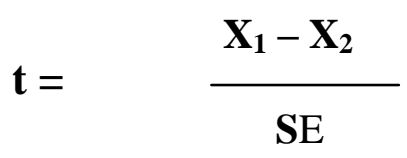

where,

$\mathrm{X}_{1}=$ Mean yield of the IPM plots

$\mathrm{X}_{2}=$ Mean yield of the Non IPM plots

$\mathrm{SE}=$ Standard error of the differences

between the two means $=\mathrm{SD} / \sqrt{\mathrm{n}}$

Where $\mathrm{n}=$ number of paired plots

$\mathrm{n}-1=$ degrees of freedom

$\mathrm{SD}=$ Standard Deviation

$\mathrm{S}=\sqrt{\text { sum of } \mathrm{d}^{2} / \mathrm{n}}-1$

Reduction in yield $(\%)=\frac{\mathbf{X}_{1}-\mathbf{X}_{2}}{\mathbf{X}_{2}}$

\section{Results and Discussion}

The mango fruit fly, $B$. dorsalis is a destructive polyphagous pest, posing threat to various fruit crops. Population dynamics of fruit fly and yield were recorded in Papparampakkam village of Tiruvallur district during 2014-15. Results showed that trap catches was high, 839.1 fruit flies per trap during July 2014, followed by August, 2014 (563.8 fruit flies/trap). The fruit fly population was low during January, 2015 to April, 2015 (Fig. 1).

The results are in accordance with Khosravi et al., (2018) who revealed that combination of methyl eugenol and malathion attracted the male mango fruit flies and hence mating would be disrupted and reduce fruit fly populations to very low levels effectively. The 
control of fruit flies at the destructive larval stage is difficult because insecticides in the form of dust or sprays cannot reach them. The ways to deal with them is to target adult flies before they start laying eggs by trapping them or using insecticides to control their populations (Mugure, 2012).

\section{Fruit yield}

Mango fruit yield was found to be high 143 $\mathrm{q} / \mathrm{ha}$ in IPM plot and in Non IPM plot the fruit yield was observed to be $112 \mathrm{q} / \mathrm{ha}$. Since, the calculated $t$ value is greater than table $t$ value the data is significantly different. The reduction in yield in Non IPM plot was 27.7 per cent (Table 1).

The net income was high Rs. 2,62,005/- in IPM plot whereas it is low Rs. 1,98,120/-in Non IPM plot. Benefit cost ratio was also found to be high in IPM plot (1:11.5) when compared to Non IPM plot (Table 2).

Table.1 Fruit yield in IPM and non IPM plots

\begin{tabular}{|c|c|c|c|c|c|}
\hline $\begin{array}{l}\text { Paired } \\
\text { plot no. }\end{array}$ & \multicolumn{2}{|c|}{ Yield (q/ ha) } & $\begin{array}{c}\text { Difference } \\
\text { in yield } \\
\text { (X1-X2) }\end{array}$ & $\begin{array}{c}\text { Deviation } \\
\text { from mean } \\
(\mathbf{d})\end{array}$ & $\begin{array}{c}\text { Square of } \\
\text { Deviation } \\
\text { (d }^{\mathbf{2}}\end{array}$ \\
\hline $\mathbf{1}$ & IPM (X1) & Non IPM (X2) & 1.0 \\
\hline $\mathbf{2}$ & 141 & 109 & 32.0 & 1.00 & 25.0 \\
\hline $\mathbf{3}$ & 147 & 111 & 36.0 & 5.00 & 16.0 \\
\hline $\mathbf{4}$ & 145 & 110 & 35.0 & 4.00 & 64.0 \\
\hline $\mathbf{5}$ & 142 & 127 & 15.0 & -8.00 & 0.0 \\
\hline $\mathbf{6}$ & 138 & 99 & 39.0 & 0.00 & 36.0 \\
\hline $\mathbf{7}$ & 147 & 110 & 37.0 & 6.00 & 4.0 \\
\hline $\mathbf{8}$ & 131 & 104 & 27.0 & 2.00 & 1.0 \\
\hline $\mathbf{9}$ & 144 & 115 & 29.0 & -2.00 & 4.00 \\
\hline $\mathbf{1 0}$ & 159 & 117 & 42.0 & -1.00 & 1.0 \\
\hline Total & 136 & 118 & 18.0 & -7.00 & 49.0 \\
\hline Mean & 143.00 & 112.00 & 31.00 & & 200.0 \\
\hline
\end{tabular}

\begin{tabular}{|l|c|}
\hline Standard Deviation & $\mathbf{4 . 7 1}$ \\
\hline Table t value & 1.833 \\
\hline Calculated t value & 20.8 \\
\hline
\end{tabular}

Table.2 Economics of IPM and Non IPM plots

\begin{tabular}{|l|c|c|c|c|}
\hline Parameters & $\begin{array}{c}\text { Cost of } \\
\text { cultivation } \\
\text { (Rs.) }\end{array}$ & $\begin{array}{c}\text { Gross income } \\
\text { (Rs.) }\end{array}$ & $\begin{array}{c}\text { Net income } \\
\text { (Rs.) }\end{array}$ & BCR \\
\hline IPM plot & 24995 & 287000 & $2,62,005$ & 11.5 \\
\hline $\begin{array}{l}\text { Non IPM } \\
\text { plot }\end{array}$ & 26280 & 224400 & $1,98,120$ & 8.5 \\
\hline
\end{tabular}

Mean of 10 plots 
Fig.1 Population dynamics of mango fruit fly during $2014-15$

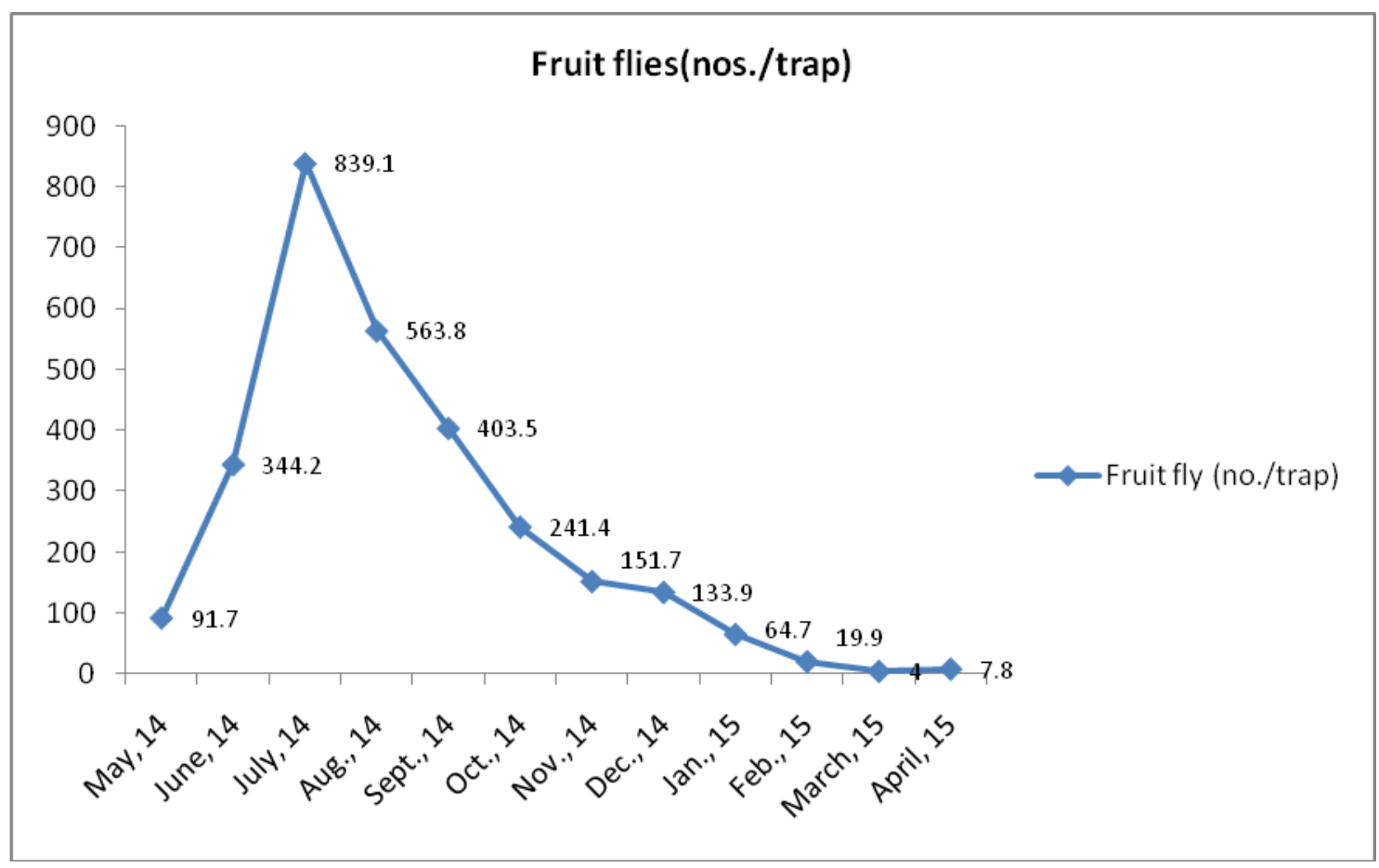

Trapping system is one of the most common tools for bio-systematic studies and biological control of fruit flies. This technique is used to determine the presence or absence of a pest in an area, track and identify distribution range, calendar time to control, effectiveness of control methods, hosts and host sequence, fluctuations in population density, spatial distribution, time of appearance and economic damage threshold and early detection of pest (Rizk et al., 2014).

\section{References}

Abdullah, K., Akram, M. and Alizai, A.A. 2002. Nontraditional control of fruit flies in guava orchards in D. I. Khan. Pakist. J. Agric. Res. 17 (2): 71-74.

Agarwal, M.L. and Kapoor, V.C. 1985. On a collection of Trypetinae (Diptera: Tephritidae) from Northern India. Ann. Entomol. 3: 59-64.

Chiu, H.T. and Chu, Y.I. 1986. The occurrence and injury of the oriental fruit fly in the Southern Taiwan. Plant Prot. Bull. 28: 313-321.

Clarke, A.R., Armstrong, K.F., Carmichael, A.E., Milne, J.R., Raghu, S., Roderick, G.K. and Yeates, D.K. 2005. Invasive phytophagous pests arising through a recent tropical evolutionary radiation: the Bactrocera dorsalis complex of fruit flies. Annu. Rev. Entomol. 50: 293-319.

Dhillon, M.K., Singh, R., Naresh. J.S. and Sharma, H.C. 2005. The melon fruit fly, Bactrocera cucurbitae: A review of its biology and management. J. Insect Sci. 5: 1-16.

Lee, W.Y. 1988. The control programme of the oriental fruit fly in Taiwan. Chinese J. Entomol. 2: 51-60.

Kapoor, V.C., Agrawal, M.L. and Grewal, J.S. 1976. Identified Indian Fruit flies (Diptera: Tephritidae) in National Pusa collection, India. Bull. Entomol. 17: 115.

Khosravi, M., Sahebzadeh, N., Kolyaie, R and Mokhtari, A. 2018. Field evaluation of 
controlling methods of mango fruit flies Bactrocera zonata (DIPTERA: TEPHRITIDAE) in the southern part of Iran. Trakia Journal of Sciences, No 1, pp 62-69, 2018

Mishra, J., Singh, S., Tripathi, A. and Chaube, M.N. 2012. Population dynamics of oriental fruit fly, Bactocera dorsalis (Hendel) in relation to abiotic factor. HortFlora Res. Spectrum 1 (2): 187189.

Rahiman, O.A., Reghunath, P. and Prasad, R.M. 1986. Prospects and problems of commercial vegetable growing in rural areas. Rural Dev. Rev. 5: 494-498.

Rizk, M.M.A., Abdel-Galil, F.A., Temerak, S.A.H., and Darwish, D.Y.A. 2014. Factors affecting the efficacy of trapping system to the peach fruit fly (PFF) males, Bactrocera zonata (Saunders) (Diptera: Tephritidae). Archives of Phytopathology and Plant Protection. 47 (4): 490-498.

Serem, A. 2010. Challenges in production and marketing of mangoes in Kenya. In:Unearthing the Gold in Mango Conference, KICC, Nairobi. February 11-12.

Singh, A. and Sardana, H.R. 2005. Research conclusions and recommendations for the on-farm IPM of tephritid fruit flies in India. Pest Manag. Hortic. Ecosyst. 11 (2): 172-180.
Sithanantham, S. 2004. Development and dissemination of IPM for vegetables in Eastern Africa. ICIPE Science Press, Nairobi, Kenya. p51.

Tandon, P.L. and Verghese, A. 1985. World list of insect, mite and other pests of mango. Technical Document No. 5, IIHR, Bangalore, $\mathrm{p} 22$.

Vargas, R.I., Harris, E.J. and Nishida, T. 1983. Distribution and seasonal occurrence of Ceratitis capitata (Wiedemann) (Diptera: Tephritidae) on the island of Kauai in the Hawaiian Islands. Environ. Entomol. 12: 303-310.

Verghese, A., Madhura, H.S., Jayanthi, P.D.K. and Stonehouse, J.M. 2002 Fruit flies of economic significance in India, with special reference to Bactrocera dorsalis (Hendel). In: Proceedings of Sixth International Symposium of Fruit flies of Economic Importance, Stellenbosch, South Africa, pp. 317-324.

Verghese, A., Tandon, P.L. and Stonehouse, J.M. 2004. Economic evaluation of the Integrated management of the oriental fruit fly, Bactrocera dorsalis (Diptera: Tephritidae) in mango in India. Crop Prot. 23: 61-63.

Ye, H. 2001. Distribution of the oriental fruit fly (Diptera: Tephritidae) in Yunnan Province. Entomologia Sinica. 8: 175182.

\section{How to cite this article:}

Sumathi, E., R. Manimaran, M. Nirmala Devi, M. Ilamaran and Agila, R. 2019. Population Dynamics and Management of Mango Fruit Fly Bactrocera dorsalis (Hendel) (Diptera: Tephritidae). Int.J.Curr.Microbiol.App.Sci. 8(01): 2705-2710. doi: https://doi.org/10.20546/ijcmas.2019.801.285 